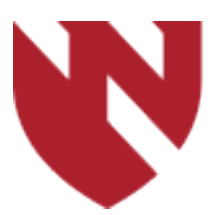

December 2019

\title{
Evaluation of a Midline Catheter Program and Effect on Central Line Associated Blood Stream Infections
}

\author{
Richard Hankins \\ University of Nebraska Medical Center \\ Mark Rupp \\ University of Nebraska Medical Center \\ Teresa Micheels \\ University of Nebraska Medical Center \\ Luana Evans \\ University of Nebraska Medical Center \\ Angela Boesch \\ University of Nebraska Medical Center
}

See next page for additional authors

Tell us how you used this information in this short survey.

Follow this and additional works at: https://digitalcommons.unmc.edu/gmerj

Part of the Higher Education Commons, and the Medicine and Health Sciences Commons

\section{Recommended Citation}

Hankins, R., Rupp, M., Micheels, T., Evans, L., Boesch, A., Hayes, K., Sy, A., , Cawcutt, K. Evaluation of a Midline Catheter Program and Effect on Central Line Associated Blood Stream Infections. Graduate Medical Education Research Journal. 2019 Dec 13; 1(1).

https://digitalcommons.unmc.edu/gmerj/vol1/iss1/69

This Conference Proceeding is brought to you for free and open access by DigitalCommons@UNMC. It has been accepted for inclusion in Graduate Medical Education Research Journal by an authorized editor of DigitalCommons@UNMC.For more information, please contact digitalcommons@unmc.edu. 


\section{Evaluation of a Midline Catheter Program and Effect on Central Line Associated}

Blood Stream Infections

\section{Creative Commons License}

\section{(c) (1) $\odot \Theta$}

This work is licensed under a Creative Commons Attribution-Noncommercial-No Derivative Works 4.0 License.

\section{Authors}

Richard Hankins, Mark Rupp, Teresa Micheels, Luana Evans, Angela Boesch, Kim Hayes, Adrienne Sy, and Kelly Cawcutt 


\section{Pseudo-Pseudotumor: A Cautionary Tale}

Brian Westerhuis and Sachin Kedar

Mentor: Sachin Kedar

Program: Neurology

Background: Idiopathic Intracranial Hypertension (IIH) is a commonly considered diagnosis and common reason for neurology consultation.

\section{Methodology: Case series}

Results: Two cases of presumed IIH presented with progressively worsening headache and reduced vision. Both had papilledema on exam and elevated CSF opening pressures on lumbar puncture. CSF contents were normal. In one, initial imaging (MRI brain) revealed the "partially empty sella" raising concern for IIH. In the other, imaging was initially unrevealing. Both were started on Acetazolamide for presumed IIH. Both patients experienced progressive deterioration of vision, papilledema and headache. The first patient was found to have extensive cerebral venous sinus thrombosis and started on anticoagulation. The second patient was found to have leptomeningeal glioma after several months and started on chemotherapy. Guidelines and recommendations for evaluating these patients are reviewed

Conclusion: Numerous processes produce elevated intracranial pressure, including cerebral venous sinus thrombosis and intracranial malignancies. "Pseudotumor cerebri" remains a diagnosis of exclusion, particularly in patients who do not fit the "classic" phenotype. There is a very real danger in prematurely closing on the diagnosis without sufficient investigation to rule out other causes. A high index of suspicion for an alternate diagnosis must remain until sufficient investigation is completed.

https://doi.org/10.32873/unmc.dc.gmerj.1.1.068

\section{Evaluation of a Midline Catheter Program and Effect on Central Line Associated Blood Stream Infections Richard Hankins, Mark Rupp, Teresa Micheels, Luana Evans, Angela Boesch, Kim Hayes, Adrienne Sy, Kelly Cawcutt}

Mentor: Kelly Cawcutt

Program: Infectious Disease

Background: Central line associated blood stream infections (CLABSI) result in increased patient morbidity. Guidelines recommend against peripheral venous catheters when access is required for longer than 6 days, leading to central venous catheter (CVCs) placement. To improve vascular access device choice, we implemented a quality improvement initiative compromised of a new vascular access algorithm with introduction of midline utilization and sought to evaluate the impact of midline use on CLABSI rates.
Methods: A prospective quality improvement assessment from October 2017 through March 2018 analyzed vascular access. When a consult was placed for a peripherally inserted central catheter (PICC) a patient would be evaluated via the vascular access algorithm for whether they should receive a midline catheter, a PICC or CVC. They were then monitored for duration of indwell and bloodstream infections consistent with reportable CLABSI definitions.

Results: In the month prior to implementation, the institutional CLABSI rate was 1.36 per $1000 \mathrm{CVC}$ (including PICC) days. Since October 2017, there have been 4588 midline catheter days, with 2 midline infections, for a cumulative rate over 6 months of 0.435 midline catheter infections per 1000 midline days. This was compared to $26,575 \mathrm{CVC}$ days, with 33 documented CLABSIs, for a rate of 1.242 per 1000 CVC days.

Conclusion: The implementation of a vascular access algorithm including midlines may reduce central line insertions and decrease CLABSIs through utilization of a lower risk device (midline). Further research into comparing additional risks and benefits of midline catheters and all styles of central venous catheters is warranted.

https://doi.org/10.32873/unmc.dc.gmerj.1.1.069

\section{Left Ventricular Assist Device (LVAD) Infections: A Single Center Experience \\ Rajendra Karnatak, Uriel Sadkovsky}

Mentor: Uriel Sadkovsky

Program: Infectious Disease

Background: Infectious complications play a major role in morbidity LVAD implantation. We report the incidence of LVAD infections at our institution over 1-year period.

Methods: Retrospective review of 36 patients who had a continuous-flow LVAD implanted between Jan 1-Dec 31, 2013. Infectious complications were defined as per ISHLT standardized definition. Only patients with a new LVAD were included. Follow-up occurred until heart transplantation or death.

Results: All patients underwent Heartmate II implantation; 55\% received the LVAD as bridge to transplantation. We identified 39 episodes of infection in $20(55 \%)$ patients. Mean age $( \pm$ SD) $52 \pm 15$ years. A total of 19175 person-days of LVAD support was followed, and average duration of LVAD support was 533 days. There were 11 (25\%) driveline infections, 9 (21\%) bloodstream infections. The most common microorganism causing bloodstream infections were coagulase negative staphylococci 4/9 (44\%), followed by Staphylococcus aureus 2/9 (22\%), Enterococci 1/9 (11\%), Streptococci 1/9 (11\%), and Candida 1/9 $(11 \%)$. Table 1 summarizes incidence of LVAD infections cases per 100-person years of LVAD support as per ISHLT definition. Two patients $(6 \%)$ developed VAD-specific cannula/pump infections, one treated with Intravenous antibiotics followed by heart transplantation, and one required long-term antibiotic suppression. Cumulative all-cause mortality at two years follow up was $19 \%$. Two-year cumulative all-cause mortality in patients with LVAD infections was lower than patients without infections $15 \%$ versus $25 \%$
(RR $0.6,95 \%$ CI 0.15 to 2.3 ), respectively. There were $8(22 \%)$ patients treated for an infection within 30 days prior to LVAD implantation, out of these 4 developed post LVAD infections, 4 did not develop infectious complications ( $20 \%$ vs $25 \%$ RR $0.8,95 \%$ CI 0.23 TO 2.7 ), respectively. The most common cause of death was withdrawal of support/ multi-organ failure, 4 patients $(57 \%)$. Only $1 / 7(14.2 \%)$ deaths during two-year period were due to infectious complications.

Conclusion: Morbidity in LVAD recipients is primarily driven by driveline infections and bacteremia. Infectious complications were not associated with increased mortality.

https://doi.org/10.32873/unmc.dc.gmerj.1.1.070 